\title{
REVIEW OF THE CONCEPT OF HUMAN CAPITAL IN SPORTS WITH AN EMPHASIS ON CAPABILITY APPROACH
}

\author{
Rasool Norouzi Seyed HOSSINI ${ }^{1}$ \\ Mohammad EHSANI \\ Hashem KOZECHIAN \\ Mojtaba AMIR
}

\begin{abstract}
This study aims to conduct a comprehensive review of human capital in sports with an emphasis on capability approach. Human capital as the most important asset of any social institution plays an important role in dynamics and progress. Several approaches are used to measure human capital; however, there is not an acceptability criterion for measuring it in terms of all social fields. Using capability approach can be considered as one of the efficient criteria which comprehensively apply human capabilities to measure human capital. Despite the significant importance of human capital and capability, there is few sports-related studies conducted on this area; therefore, researchers are highly recommended to undertake qualitative and quantitative research on the subject.
\end{abstract}

Keywords: sports, human capital, competitive advantage, physical capital.

JEL classification: I 19, I 29

\section{Introduction}

In the recent decade, organization management has recognized that human capital is of the highest importance in achieving sustainable competitive advantage. In today's world where knowledge and communication with others has assumed importance more than ever, human capital which is indicative of body of knowledge, technical skills, creativity, and organizational experience exceeds other items in importance. Similarly, workforce is considered as productive assets rather than costly assets (Hendricks, 2002: 199). Service organizations among which lie sports organizations should modify their management methods of human resources in order to meet the current needs of variable environments. The first step towards is to consider staff and employees as productive assets and capitals which influence all other physical capitals. It emphasizes the service organizations' need to detailed information on quality and characteristics of organizational human resources and

${ }^{1}$ Rasool Norouzi Seyed Hossini, Ph.D student, Tarbiat Modares University, Tehran, Iran

Mohammad Ehsani, Corresponding author - Associate professor, Tarbiat Modares University, Tehran, Iran, Email: ehsani@modares.ac.ir

Hashem Kozechian, Associate professor, Tarbiat Modares University, Tehran, Iran

Mojtaba Amir, Associate professor, Tehran University, Tehran, Iran 
on how these characteristics have been wired to the major mission of organization (Valeriya, 2006:35).

Given the dramatic changes in social and organizational contexts and intensity of competition in today's world, organizations are seeking to attract and more importantly retain and develop manpower for the performance of their current and future processes more than ever. Unquestionably, human capital is a factor that affects the growth and survival of the organization more than any other factor. Today, the importance of human capital in all fields has increased in such a way that modern growth theory considers human capital accumulation due and even regards human capital as a factor effective in economic growth and development of communities (Becker, 1964).

\section{Conceptualization of human capital}

The concept of human capital is indebted the efforts of Theodor W. Schultz (1963) and Gary S. Becker(1964) as two contemporary economists that have changed human capital theory from its very early classical stages into the advanced and analytical modern version of the day. They indicated that human capital not only is obtained through the accumulation and storage of education, but it is also created through other countless ways. Many economists note that this kind of capital is intangible and impalpable and constitutes an inseparable part of human body, soul, and brain which constantly accompanies him and does not get detached from it for a moment. It should be mentioned that Becker's effort to introduce the concept of human capital has been much brighter and effective than that of Schultz. In fact, Gary Becker entered this concept into economic literature with the publication of a book, entitled Human Capital in 1964. This book has been a standard reference for many of the researches in this field. He believes that the concept of human capital is rooted in economic literature (Becker, 1996). Indeed, qualitative characteristics of individuals are their capital. Therefore, the optimal maintenance and use of this valuable asset has been put on the agenda of most organizations, especially service organizations, such as sports organizations. Moreover, Price (2007) states that economic growth of every organ to a relatively great extent depends on the skilled human resources at the organizations' disposal.

Horibe (1999) suggests that there is a difference between human capital (such as skill, knowledge, and intelligence) and structural capital (such as database systems which provide the necessary infrastructure for optimal use of social capital). However, aspects of human resources regard both human and structural capital based on operational programs which includes encouraging learning more and using existing knowledge. It should be mentioned that human capital is neither considered physical capital nor financial capital, but it is defined as knowledge, skill, creativity, and health (Becker, 2002). Becker (2002) pointed out that human capital, physical capital, and financial capital are all some forms of capital; 
however, the difference here lies in the fact that it is not possible to separate one from his/ her skills, health, and values while this possibility holds true about one's assets and properties. This means that the most stable and reproducible capital is human capital. Several definitions have been proposed for human capital, each of which places emphasis on different properties and characteristics of human capital. For example, Houtz (1998) introduces human capital at the time, experience, purpose, and capabilities of a family member who may be involved in the production process, introduces (Burud \& Tumolo, 2004). In another definition, human capital is the investment on human resources in order to increase their efficiency with the aim of productivity in the future. Based on this definition, it can be said that human capital is a coherent set of qualitative, educational, skill-based, and cultural characteristics of people in organizations that creates added value for the organization (Becker 1996). In other definitions, the concept of human capital represents that the qualitative characteristics of human are some sort of capital since these characteristics can be converted into a source of additional revenue and/ or of more abundant satisfaction and fulfillment. In most cases, organizational success depends on the individuals who have higher levels of competencies. In such circumstances, these individuals become valuable assets to their organization (Losey, 1999: 99). Accordingly, human capital can be regarded as one of the production factors that can have high added value to the organization and the community. A newborn definition of human capital views human capital as a set of attributes, life trade, knowledge, creativity, innovation, and energy which people opt for in order to invest in their business (Lawson \& Limbrick, 1996: 69). 


\section{Theoretical perspectives on human capital}

Human capital theorists argue that human capital is embodied in individuals in the form of skill, knowledge, and expertise and increase productivity levels, service quality, and earnings and influences many of their decisions in all life areas. It is noteworthy that there are three basic views on human capital where the first one places emphasis on the unique aspects of individuals. In this view, human capital is related to manpower assets and capabilities. This view is right the other of labor force concept in the classical perspective (Schultz, 1961: 22). The second view, focused on human capital, puts the major emphasis on its processes.

In this view, knowledge and skill are two key elements that are greatly assigned importance during educational activities, such as formal education and vocational skills (f Fitzsimons \& Peters, 1994). The third one takes a production-based perspective on human capital. Human capital is known as a combination of such factors as education, experience, academic studies, intelligence, energy, work habits, and initiative which influence value and marginal product of workers. Another definition provided by this perspective considers human capital as a set of skills and knowledge to perform activities which leads to production and economic value. As a result, human capital can simultaneously contain both concepts; that is, it can be a means of production and create a specific and endogenous value for the organization, as well. This inherently means a production for human capital. Overall, it can be said that human capital is synonymous with knowledge embedded in all individual and organizational levels or a society (Huselid, 1995). From the individualistic perspective, the possibility of an increase in an individual's income is derived from his/ her productivity. Here, individuals can potentially experience a growth and progress in the layers of domestic markets. From the organizational perspective, organizational productivity is the result of a set of updated capabilities and capacities of organizations and its dynamic organization culture. Last but not least, from the social perspective, human capital is capable of creating mechanisms for establishing democracy, political stability and respect for human rights across the society and expanding them. Social capitals lead to public awareness of social factors and make it possible to increase social awareness from the components inside the community (Becker and Gerhart, 1996: 801-779). Therefore, the association between human capital and social awareness has been established a strong mutual relationship towards social-political development. 


\section{Measurement of Human Capital}

There is no consensus among experts on the measurement approach of human capital. Accountants, economists, human resource professionals, and researchers are all interested in measuring human capital with a different approach. Indexes can be divided into direct and indirect ones and/ or they can be measured at the individual or organization level. Organizational indexes are categorized into two sets. The first type includes those indexes that accountants use to describe the value of a business and accountants and financial community view human capital as an intangible business assets. Several accounting methods are available for the evaluation of intangible assets. A vast number of experts compare the superior value of an organization based on tangible assets and earnings in the business, including income and tangible and intangible assets.

The problem with this approach is that the intangible assets entail future and trademark value of organizations similar to such factors as anticipated earnings; therefore, this definition is limited by the factors with no relevance to human capital. The second type includes organizational indirect index of human capital which is the great collection of some factors that reflect operating costs of human resource programs. These indexes represent the efficiency of human resource programs and are based on the assumption that spending more on education leads to greater benefits from human capital. It is important to note that human capital refers to the items that are owned by individuals; however, things perform such activities that have no economic value for them and for their organization. Measuring human capital indices provides the organization with this opportunity to express their expectations of the staff, become aware of what happens within the organization, identify those performance gaps needing analysis and modification, provide feedback through the comparison of current performance standads with the widely-accepted framework, recognize the performance that deserves rewarding, and support the decisions pertaining to resource allocation, scheduling and operations(Foong \& Yorston, 2003: 22). Capability approach is one of the latest criteria for measuring human capital.

\section{Capability Approach}

In today's highly competitive world of business; technology, superior products, and constant resources are the advantages of entry to market. Many organizations have recognized that the key to success in competition is the ability of their workers to maximize these points (McLagan, 1989). However, an organization may find it difficult to determine the critical capability of staff to achieve success. Behaviors necessary for the transfer of the effective performance of an organization to another organization and from one role to another role are very different. Thus, most of the companies have used capability models to identify skills, knowledge, personal attributes essential for successful job-related performance, and to reach certainty of human resource systems focus on human capital development. Fundamental 
changes in practices, processes, and business of human resource management over the past decades have caused human capability approach to attract the attention of pioneering organizations. The concept of capability is needed to be deeply described in order to gain a better understanding of the capability approach. American Heritage Dictionary defines capability as "the quality of being capable; practical ability". The definition gives us a good and general description, but it does not clearly state what the organization measures (Iversen, 2000). Oxford Dictionary (2003) defines capability as the power or ability to perform a task. Cave (1993) defines capability as the consequence of the pertinent utilization of knowledge and skills. In other words, capability means skills in addition to knowledge (Cave, 1993: 123). Thompson \& Harrison (2000) regards capability as a combination of knowledge, skills, and abilities in a particular job which allows a person to achieve success in their tasks. As it is observed, this definition has added the component of ability to other components of capability. Philpot et al (2002) define capability as a combination of skills, knowledge, and attitudes needed to effectively perform a role. In this definition, the component of attitudes has replaced the component of skills. In another definition, the component of motivation has been added to replace both skills and attitudes. According to Hantstin (2000), capability is generally defined as a set of interrelated behaviors or activities, types of knowledge, skills, and motivations that are considered behavioral, technical, and motivational prerequisites for successful performance in a specific job or role (cited by Ruth, 2006: 226-206). A more relevant definition widely accepted by human resource professionals in the corporate environment is as follows "essential characteristic of a person which results in effective or superior performance in a job" (Klemp \& George, 1998). Another precise definition regards it as the combination of proposals of hundreds of human resource development specialists at a conference gathered in Johannesburg in 1995 about the capabilities. According to them, capability means "The combination of interrelated knowledge, skills, and attitudes which influence the magnitude of one's job (role or responsibility), are directly associated with job performance, can be measured unlike the expected high standards, and can be improved by means of training and development"( Rodriguez et al., 2002). Based on these definitions, capability approach describes the specific combination of knowledge, skills, and attributes required to effectively play a role in the organization and is used as a human resource tool for selection, training, development, assessment, and succession planning (Ruth, 2006). Capability approach exactly refers to the point by giving response to the two following questions: What skills, knowledge, and attributes are required to do the job? Which behaviors have the most direct impact on the performance and success on the job?

In capability approach, what one can do (capability) and one does (performance) are of importance (kuklys, 2005: 12). From the perspective of the capability approach, if one's achieved performance has been the only possibility, it shows that 
there has not been any other possibility to choose and act in their capability package (function); since one's ability or capability is dependent upon different functions they may perform. An important issue that must be addressed is whether the enjoyment of basic capabilities such as education, training, nutrition, and healthy body suffice them to expand the range of possibilities to opt for the desired life or to add their set of capabilities to prevent the collapse in crisis. Obviously, there are circumstances beyond the individual's decisions and actions. Even the acquisition of these individual capabilities also depends largely on the social and environmental conditions. If the social and environmental context is not prepared, the individual's ability will not be developed or if it is developed, it will not function. Today, new approaches such as sustainable development and human development arise towards the achievement of the ultimate goal of development that is human according to neoclassical economists. It is mistakenly thought that human development and sustainable development are opposite strategies. This attitude is wrong. Human development entails sustainable development and sustainable development deals with those aspects of human development which are related to the environment and future generations.

\section{Capabilities and human capital in Sports}

The important point about the concept of human capital is that human capital is durable; however, it must be borne in mind that the service time of this capital is limited. Human capital needs maintenance and repair, and substitution if necessary; so that it does not get wasted like physical capitals that are out of work. Like the increasing changes in levels of international sports, if this type of capital cannot adapt itself to technological changes, it will be phased out before depreciation. Growing evidence indicates that the activities of human capital play an important role in improving organizational performance. Evidence suggests a positive and significant output as a result of investment in human capital in a range of individual skills to organizational outcomes and outputs such as increased levels of service, impressive productivity, profitability, organizational performance in society, and the improvement of their production quality. These outputs are highly crucial for sports organizations since the final product in sports is more service-based and upgrading sports services plays a critical role in the survival and development of organization (Smith, 2008: 104).

Modern governments are aware of the role of human capital in economic growth. Therefore, they establish some organs and departments in government body to develop and improve human capital. For example, in order to enhance human capital, the British Government has founded local council of skills in Great some occupational areas where Skills Active has the responsibility of sports and active leisure time. The main responsibility of Skills Active is to identify and assess activities necessary for sports and leisure areas and develop these skills to enhance active workforce in this area (Wolsey, Abrams, Minten, 2011). Another issue is how to incorporate and develop skilled employees. For example Skills Active 
(2006) announced that only 26 percent of sports organizations staff enjoy professional competencies and capabilities. Based on these measures, it should be noted that the maintenance and identification of human capital and the suggestion of guidelines for its development are amongst most important responsibilities of sports organizations.

Today, in every society, sports functions and plays a vital role in the economic, social, and cultural life. Without efficient and dynamic sports organizations, the goals preset by the statesmen cannot be realized. There are valuable resources in each sports organization, each of which plays an important role in the success of organizations, but human role as the most important asset of any organization is more important than other sources (Coleman (1988). Therefore, the management of this valuable asset and efficient use of it is one of the most important priorities that must be regarded by every sports organization. Since human resources are the most valuable factor of production and the major source of competitive advantage and key features in any organization; therefore, human capital management is considered as the infrastructure for the success of any organization. Since most products offered by sports organizations are intangible in nature, the sort of presenting and managing them plays an important part in the survival and progress of the organization. As well, the existence of numerous beneficiaries in sports puts sports organizations in competitive situations and makes them try to use human capital management approaches to advance their goals. According to this principle that there is no accepted solution capable of meeting the needs of sports organizations in all organizational conditions, sports organizations should apply various approaches based on their conditions and situations so that they can primarily guarantee their own survival and then their progress and development. Given this situation, the development of human capital in sports is one of the appropriate methods of survival and progress in international levels. Since sports environments are dynamic atmospheres where human plays a crucial part, the development of capabilities and consequently human assets can lead to the improvement of performance indexes at national and international levels. According to this aspect, Nicholson \& Hoye (2008: 43) argue that the full potential of sports is needed to be used to come with sports development and complexities and dilemmas in the way should be reduced to the extent possible. Accordingly, they believe that for the achievement of sports development, it is strongly needed to have a paradigm shift in participation, social development, social cohesion, harmony, sharing knowledge, expertise, and use of aid paradigms. Studies conducted in relation to the development of capabilities and development of human capital as the most valuable asset of any organization show the strong need to human capital development to sustainable development.

\section{Studies on human capital in Sports}

Vol. VI • Nr. 2 • 2014 
Unfortunately, few studies have been conducted pertaining to human capital development and also capability approach in sports. Here we review some of them.

Giulianotti (2004: 369-355) in his study entitled "Human rights, globalization and sentimental education: the case of sport" states that in order to be able to develop human capital in sports, it is necessary to provide the youth with the chance of participation in decision-makings, identify and resolve conflicts existing in the exploitation of working relationship, motivate individuals to idealism, create relationships based on mutual respect and trust, create opportunities for the development of various aspects of human capital, particularly through the use of volunteer opportunities in the areas of coaching and training. He believes that if an organization takes these measures, it will look more attractive to aid agencies and their investment. Such organizations can open up better opportunities to develop their human capital through the relationship between the characteristics of different forms of social relations and relevant resources.

Kruse (2006: 8) in a study on assets available in sports for development, states that directions and prospects for human capital development in sports organizations are interpreted in different ways due to the vague and ambiguous issues and also multiple interpretations of the capitals in sports. As well, due to lack of clearly defined goals in sports, it is difficult to assess the development of human capital (cited by Nicholson \& Hoye, 2008: 41). In this regard, Hognestad (2005) established a governing approach for the development of human capital in sports in which shift in economic development policy was feasible along with economic issues towards the role of culture in development processes. In this approach, development as an expansion of individuals' developmental capabilities was introduced with an emphasis on the role of cultural issues in order to determine the main thinking line and developmental measures. Here, not only the dominant economic paradigm of development was emphasized, but also the culture and issues related to the consolidation and completion of development of sports infrastructure in sports was used. Saavedra (2005) in his study entitled "Women, Sport and Development" strongly emphasized the role of women in developmental models towards human capital development in sports, especially at a time when traditional social relations based on exploitation exist. He believes that all existing abilities and opportunities in individuals should be used through a nondiscriminatory perspective in order to achieve optimal development.

Woolcock and Narayan (2000) in their study entitled "Social capital: Implications for development theory, research, and policy" stated that the paradigm dominant over development theories in social and human capital is a political-economic paradigm. They mentioned that social media such as sports, social networks and relationships that are one of the most important factors of development are paid less attention; rather, the emphasis placed on potential sources and political issues. Munro (2005) in their study entitled "Role Models: Is Anything More Important for Future Development?" acknowledges that it is highly needed to establish a link 
between sports and social services in order for human capital development in sports (with an emphasis on football as a collective social structure). For the realization of human capital development in sports, he also placed a particular emphasis on collective learning, participatory decision making, experiential learning, availability of opportunities required to pursue an academic education, and opportunities required to upgrade knowledge and skills in executive procedures. Abraham, Harris \&Auerbach (2013) in their study entitled "Human Capital Evaluation in Professional Sport" suggests that turnover rate, the broadcasting right, sponsorship, ticket sales, concessions, and whole sales turnover of stadiums and sports clothing should be considered in professional sports to determine the available human capital. They also stated that the growth performance of the team as a key indicator should be considered to determine the exact degree of human capital available in Professional Sports Teams.

Ferkins, Shilbury, \& McDonald (2009) in a study entitled "Board involvement in strategy: advancing the governance of sport organizations" sought to examine how national sporting bodies may develop their strategic capabilities. They reached the conclusion that executive sporting bodies need to be active participants in the process of strategy formulation and also endeavor to adapt and integrate strategies in their processes. Another finding of that study was that intra-organizational relationships affect the development of strategic capabilities of sports organizations.

Accordingly, NGOs can boost their strategic capabilities through collaborative cooperation with local organizations and also through the application of powersharing approach that can lead to the development of local capacity.

\section{Conclusion}

A very important point in terms of human capital and related research is that research, evaluation, and management of human resources is probably more difficult compared to other organization sources since the rarest and most complex resources in today's knowledge-based economy are human resources. Most managers concentrate their strategies on tangible factors of organizations such as technology and the use of physical and financial resources. This, in itself, cannot lead to competitive advantage for organizations due to the characteristics of today's global economy and the emergence of such phenomena as globalization and the increasing growth of technology and use of new technologies in presenting various new products. Therefore, organizations concentrate on other factors such as human and intellectual capital to achieve competitive advantage and survival growth.

This subject is of importance in that McKinsey (1990), with the publication of the book entitled war for talent, argues this point that top managers of enterprises increasingly focus on the needs of the organization to effectively attract, motivate, 
develop, and retain talents. According to the above-mentioned points, today human capital is more important than any other tangible resources for organizations (Guthridge, Komm, \& Lawson, 2008).

In addition to the above-mentioned items, it should be noted that human capital is not only a novel concept in human resources; but it is also a strategic issue for sports organizations and has experienced an increasing growth in organizations and societies. Accordingly, the efficient use of human capital can lead to the desirable implementation of organizational strategies. Moreover, human capital plays an important role in the prosperity of individuals, improvement of living standards and income, increase of knowledge and skills, production capacities, economic growth, and poverty reduction. As well, due to the fact that the sports world is experiencing new developments with the arrival of new technologies, the importance of human resources will be realized more than ever. Thus, there is very few and limited number of research done on human capital and capability approach. Therefore, it is highly needed further new research will lead to the identification of neglected aspects in human capital in sports.

\section{REFRENCESS}

1. Abraham, R. Harris, J. Auerbach, J, 2013. Human Capital Valuation in Professional Sport, International Journal of Business, Humanities and Technology, Vol. 3 No. 3, pp. 12-21

2. Becker, B. \& Gerhart, B, 1996. "The Impact of Human Resource Management on Organizational Performance: Progress and Prospects." Academy of Management Journal 39, 4: 779-801

3. Becker, G, 1964. Human Capital, New York: Columbia University Press.

4. Becker, G. S, 1996. The Economic Way of Looking at Behavior: The Nobel Lecture. Essays in Public Policy, No. 69, Hoover Institution, Stanford University, Palo Alto, CA.

5. Becker, G.S, 2002. 'The age of human capital'. Education in the Twenty-First Century. Retrieved from the World Wide Web: http://economics.dlut.edu.cn/ uploadfiles/20081106200614853.pdf, accessed. 11 August 2010.

6. Burud, S. \& Tumolo, M. 2004. Leveraging the new human capital: Adaptive strategies, results achieved, and stories of transformation. Palo Alto, CA: Davies-Black Publishing.

7. Cave, E. \& McKeown, P., 1993.Managerial Effectiveness: The Identification of Need. Management Education and Development,Vol 24, No. 2, pp. 122-137.

8. Coleman, J., 1988. Social capital in the creation of human capital. American Journal of Sociology, 94, 95-120. 
9. Ferkins, Lesley, Shilbury, David and McDonald, Gael, 2009. Board involvement in strategy: advancing the governance of sport organizations, Journal of sport management, vol. 23, no. 3, pp. 245-277.

10. Fitzsimons, P. \& M. Peters, 1994. "Human capital theory and the Government's Industry Training Strategy", Journal of Education Policy, 9, (3): 245-266.

11. Giulianotti, R., 2004. Human rights, globalization and sentimental education: The case of sport. Sport in Society, 7 (3), 355-369.

12. Guthridge, M.; Komm, A. B. \& Lawson, E., 2008. "Making talent a strategic priority." The McKinsey Quarterly, 1: 49-59.

13. Hendricks, Lutz, 2002. "How Important is Human Capital for Development?" American Economic Review, № 92 (1), No. 1, pp. 198-219.

14. Hognestad, H. ,2005. Norwegian Strategies on Culture - and Sports Development with Southern Countries, a presentation to the Sports Research Forum, Australian Sports Commission, Canberra, 13-15 April.

15. Huselid, M. A., 1995. "The Impact of Human Resource Management Practices on Turnover, Productivity, and Corporate Financial Performance." Academy of Management Journal 38: 635-672.

16. Iversen, Ole I,2000. Managing people towards a work force, Part A Managerial competencies. Presented at the 8th World Congress on Human Resource Management, Paris.

17. Klemp Jr., George O., 1998. Leadership Competencies: Putting It All Together, working paper, Cambria Consulting, lnc., Boston, Massachusetts

18. Kuklys, wiebke, 2005.; Amartya Sen's capability approach; springer.

19. Lawson, T. E. \& Limbrick, V., 1996. Critical competencies and developmental experiences for top HR executive. Human Resource Management, 35, 1, 67-85.

20. Losey, M., 1999. Mastering the competencies of HR management. Human Resource Management. Vol. 38, No. 2., 99-102.

21. McLagan, Pat, 1996. Competency models: Great ideas revisited. Training \& Development; Jan 1996; 50, 1; ABIIINFORM Global pp. 60 -64

22. Munro, B., 2005, Role Models: Is Anything More Important for Future Development? Role Models Retreat, Laureus Sport for Good Foundation, 23-24 November, Pretoria, South Africa.

23. Nicholson. M., Hoye, H., 2008. sport and social capital, UK ,Elsevier, Oxford.

24. Nunnally, J. C, 1978. Psychometric theory (2nd ed.). New York: McGraw Hill

25. Price, A., 2007. Human Resources Management in a Business Context. London: Thomson Business Press.

26. Rodriguez, donna \& et al ,2002. Developing competency models to promote integrated human resource practices. Human resource management, fall 2002, vol. 41 , no. 3 , pp. 309-324

27. Ruth, Damian, 2006. Frameworks of managerial competence: limits, problems and suggestions. Journal of European Industrial Training; 30,2/3; 
ABI/INFORM Global pp. 206 -226

28. Saavedra, M., 2005. Women, Sport and Development, Sport and Development International Platform. Available at http://www.sportanddev.org/data/ document/document/148.pdf .

29. Schultz, T. Paul., 1994. "Human Capital Investment in Women and Men: Micro and Macro Evidence of Economic Returns." San Francisco, CA: ICS Press.

30. SkillsActive, 2006a. Analysis of Gaps and Weaknesses. London: SkillsActive.

31. Smith, A, 2008. Introduction in sport marketing. USA, Published by Elsevier Ltd

32. Thompson, J. E., Harrison, J., 2000. Competent managers the development and validation of a model using the Mel standards. The Journal of Management Development; 2000; 19,9/10; pp. 836-852

33. Valeriya, Kravtsova ,2006. "The importance of human capital measurement in the organization development", Tomas Bata University in Zlin, faculty of Management and Economy,

34. Wolsey. C, Minten. S, Abram. J ,2011. Human resources management in the sport and leisure industry, Inc. Routledge.

35. Woolcock, M. \& Narayan, D., 2000. Social capital: Implications for development theory, research, and policy. The World Bank Research Observer, 15 ( 2 ), 225-249. 